\title{
Non-invasive predictors of prognosis of Asian patients with histopathologically-confirmed lean nonalcoholic fatty liver disease
}

Soichi Iritani ${ }^{1}$, Norio Akuta ${ }^{1 *}$, Yusuke Kawamura', Akira Kajiwara' ${ }^{1}$ Kayoko Kasuya', Shunichiro Fujiyama', Hitomi Sezaki ${ }^{1}$, Tetsuya Hosaka ${ }^{1}$, Masahiro Kobayashi ${ }^{1}$, Mariko Kobayashi ${ }^{2}$, Satoshi Saito ${ }^{1}$, Fumitaka Suzuki ${ }^{1}$, Yasuji Arase ${ }^{1}$, Kenji Ikeda', Yoshiyuki Suzuki ${ }^{1}$ and Hiromitsu Kumada ${ }^{1}$

\begin{abstract}
Background: The prognostic factors of morbidity and mortality in patients with lean NAFLD (body mass index $<25.0 \mathrm{~kg} / \mathrm{m}^{2}$ ) are unknown.

Methods: In this retrospective study, 446 Japanese patients with histopathologically-confirmed NAFLD (lean NAFLD, $n=170$ ) were followed for liver events, cardiovascular events, type 2 diabetes mellitus, and non-liver malignancies. The median observation period was 4.6 years. We also investigated the predictors of severe fibrosis (stage $3-4$ ) and mortality in lean NAFLD patients.
\end{abstract}

Results: Glycolipid metabolic markers, liver function tests, NAFLD fibrosis score (NFS), and histological scoring were significantly lower in lean NAFLD patients than in non-lean NAFLD. The incidence of liver cancer was higher while that of T2DM was lower in lean NAFLD. Kaplan-Meier analysis showed no significant difference in overall survival between the lean and non-lean NAFLD. Multivariate analysis of data of lean NAFLD identified NFS $\geq-1.455$ as significant independent predictor of severe fibrosis, while history of liver cancer and NFS $\geq-1.455$ were predictors of overall survival.

Conclusions: Although patients with lean NAFLD have better histopathological and biochemical profile compared to patients with non-lean NAFLD, the prognosis is not different between the two groups. Lean NAFLD patients with NFS $\geq-1.455$ or history of liver cancer should be monitored carefully during follow-up.

Keywords: NAFLD, NASH, Lean NAFLD, Overall survival, Prognosis, Mortality, Fibrosis, NAFLD fibrosis score, NFS, Liver cancer

\section{Background}

Nonalcoholic fatty liver disease (NAFLD) is the most common liver disease worldwide [1-6]. Liver pathology ranges from the typically benign nonalcoholic fatty liver

\footnotetext{
*Correspondence: akuta-gi@umin.ac.jp; norioakuta@toranomon.gr.jp ${ }^{1}$ Department of Hepatology, Toranomon Hospital and Okinaka Memorial Institute for Medical Research, 2-2-2 Toranomon, Minato-ku, Tokyo 105-8470, Japan

Full list of author information is available at the end of the article
}

to nonalcoholic steatohepatitis (NASH), but it sometimes progresses to liver cirrhosis, hepatocellular carcinoma, and liver failure [7]. In Japan, follow-up of obese patients with NAFLD is mandatory, with the aim of reducing the chance of insulin resistance and preventing disease progression [8]. Most lean persons with NAFLD display insulin resistance and altered body fat distribution even though they have less severe metabolic disturbances than overweight NAFLD. Lean NAFLD has been defined 
as body mass index $(\mathrm{BMI})<25.0 \mathrm{~kg} / \mathrm{m}^{2}$ [9]. In Japan, we often encounter lean NAFLD patients in daily practice.

The prognosis of lean NAFLD is considered to be better than that of obese NAFLD [10]. However, a higher overall mortality was reported in patients with lean NAFLD compared with obese NAFLD patients in an 11-year follow-up study, despite presentation with a healthier metabolic profile, including low insulin resistance [11]. Moreover, lean NAFLD has been reported to be independently associated with increased risk of all-cause and cardiovascular mortality compared with lean individuals without NAFLD [12]. To date, the prognosis of lean NAFLD is still unknown in Japan.

The present study was designed to define the clinical features of histopathologically-confirmed lean NAFLD patients. Furthermore, by using non-invasive tests, we analyzed the data to obtain clinically meaningful prognostic factors and predictors of severe fibrosis and survival.

\section{Methods}

\section{Patients}

Patients admitted to our hospital with liver dysfunction and/or fatty liver, diagnosed by clinical examination, laboratory tests and abdominal ultrasonography, between 1976 and 2019, underwent liver biopsy. Histopathological examination confirmed the diagnosis of NAFLD in 446 of these patients. These patients included those in whom histopathological examination showed microscopic changes consistent with steatosis in at least $5 \%$ of hepatocytes and patients with history of alcohol intake of $<20 \mathrm{~g} /$ day. The median duration of follow-up from diagnosis to death or last visit was 4.6 years (range $0.0-43.5$ years). The clinical features of the patients at the time of histopathologic diagnosis of NAFLD are summarized in Table 1. We excluded patients with (1) underlying liver disease (e.g., viral hepatitis, autoimmune hepatitis, druginduced liver disease, or primary biliary cholangitis); (2) systemic autoimmune diseases (e.g., systemic lupus erythematosus or rheumatoid arthritis); and (3) metabolic diseases (e.g., hemochromatosis, $\alpha$-1-antitrypsin deficiency, or Wilson's disease).

The study was conducted in compliance with the International Conference on Harmonization Guideline for Good Clinical Practice (E6) and the 2013 Declaration of Helsinki. The study protocol was approved by the Toranomon Hospital Institutional Review Board (\#953). Written informed consent for liver biopsy was provided by all patients.

\section{Diagnosis and follow-up}

In this study, we selected the following liver-related events for study outcome: liver cancer, hepatic
Table 1 Background factors at the time of liver biopsy

\begin{tabular}{|c|c|}
\hline$n$ & 446 \\
\hline Age & $52(18-87)$ \\
\hline Sex, male/female & $268 / 178$ \\
\hline Body mass index $\left(\mathrm{kg} / \mathrm{m}^{2}\right)$ & $26.3(18.1-42.4)$ \\
\hline History of liver cancer, yes/no & $29 / 416$ \\
\hline History of non-liver malignancy, yes/no & $39 / 405$ \\
\hline Type 2 diabetes mellitus, yes/no & $147 / 297$ \\
\hline Dyslipidemia, yes/no & $151 / 294$ \\
\hline Hypertension, yes/no & $200 / 246$ \\
\hline Hyperuricemia, yes/no & $46 / 399$ \\
\hline Smoking, yes/no & $98 / 338$ \\
\hline Albumin (g/dL) & $4.1(2.8-6.9)$ \\
\hline Aspartate aminotransferase (IU/L) & $44(12-378)$ \\
\hline Alanine aminotransferase (IU/L) & $69(13-783)$ \\
\hline Gamma-glutamyl transpeptidase (IU/L) & $71(11-990)$ \\
\hline Hemoglobin (g/dL) & $14.6(6.5-18.7)$ \\
\hline Platelet count $(\times 104 / \mu \mathrm{L})$ & $21.2(4.0-47.1)$ \\
\hline Triglyceride (mg/dL) & $139(31-1088)$ \\
\hline Total cholesterol (mg/dL) & $203(101-370)$ \\
\hline High-density lipoprotein cholesterol (mg/dL) & $45(14-86)$ \\
\hline Low-density lipoprotein cholesterol (mg/dL) & $121(27-243)$ \\
\hline Fasting blood sugar (mg/dL) & $103(65-287)$ \\
\hline Glycated hemoglobin (\%) & $6.0(4.3-12.6)$ \\
\hline Ferritin (ng/mL) & $228(1-2067)$ \\
\hline NAFLD fibrosis score & $-1.844(-7.060$ to 3.394$)$ \\
\hline \multicolumn{2}{|l|}{ Genetic variation $(n=314)$} \\
\hline PNPLA3 rs738409, CC/CG/GG/not done & $54 / 129 / 131 / 132$ \\
\hline TM6SF2 rs58542926, CC/CT/TT/not done & 237/70/7/132 \\
\hline HSD17B13 rs6834314, AA/AG/GG/not done & $161 / 132 / 25 / 128$ \\
\hline \multicolumn{2}{|l|}{ Histopathological findings $(n=446)$} \\
\hline Steatosis, 5\%-33\%/ 33\%-66\%/>66\% & $164 / 167 / 112$ \\
\hline Ballooning, none/few cells/many cells & $40 / 283 / 120$ \\
\hline $\begin{array}{l}\text { Lobular inflammation, no foci } /<2 \text { foci } / 2-4 \\
\text { foci }>>4 \text { foci per } 200 \times \text { field }\end{array}$ & 28/254/147/14 \\
\hline NAFLD activity score, $\leq 2 / 3,4 / \geq 5$ & $35 / 190 / 218$ \\
\hline Fibrosis stage, $0 / 1 / 2 / 3 / 4$ & $51 / 182 / 69 / 110 / 34$ \\
\hline
\end{tabular}

Data are number of patients or median (range) values

encephalopathy, esophagogastric varices with bleeding, ascites, and jaundice. Other outcomes included cardiovascular events (e.g., coronary artery disease, heart valve disease, arrhythmia, heart failure, hypertension, orthostatic hypotension, shock, endocarditis, diseases of the aorta and its branches, disorders of the peripheral vascular system, and stroke), type 2 diabetes mellitus (defined as high fasting blood glucose level $\geq 126 \mathrm{mg} / \mathrm{dL}$, high hemoglobin A1c $\geq 6.5 \%$, use of glucose-lowering agents, or self-reported history of clinical diagnosis), and nonliver malignancy. Mortality was evaluated for all patients. Hematologic and biochemical data were collected at least 
twice yearly after the diagnosis of NAFLD. Ultrasonography, computed tomography, and/or magnetic resonance imaging studies were conducted at least once annually during the follow-up.

\section{Liver histopathology}

Liver biopsy specimens were obtained using a 14-gauge modified Vim Silverman needle (Tohoku University style; Kakinuma Factory, Tokyo, Japan), a 16-gauge core tissue biopsy needle (Bard Peripheral Vascular, Inc., Tempe, AZ), or surgical resection. Liver biopsy samples $>1.5 \mathrm{~cm}$ and/or containing more than 11 portal tracts were considered adequate for examination and diagnosis. The specimen was fixed in $10 \%$ formalin and cut into sections, which were subsequently stained with hematoxylin and eosin, Masson trichrome, silver impregnation, or periodic acid-Schiff after diastase digestion. Four pathologists (Dr. Keiichi Kinowaki, Dr. Fukuo Kondo, Dr. Toshio Fukusato, and Dr. Takeshi Fujii), who were blinded to the clinical findings evaluated each of the specimens, and the final assessment was reached by consensus. Steatosis grades $0,1,2$, and 3 corresponded to steatosis of $<5 \%, \geq 5-<33 \%, \geq 33-<66 \%$, and $\geq 66 \%$ of hepatocytes, respectively. Lobular inflammation with no foci, $<2$ foci, $2-4$ foci, and $\geq 4$ foci per $200 \times$ field was scored $0,1,2$, and 3 , respectively. Hepatocyte ballooning of none, few, and many cells was scored as 0,1 , and 2, respectively. NAFLD activity score represents the sum of scores of steatosis, lobular inflammation, and hepatocyte ballooning (range $0-8$ points) [13]. Fibrosis stage was defined as $0,1,2,3$, and 4 using the defined criteria [13, 14]. NASH was defined according to the fatty liver inhibition of progression (FLIP) algorithm [15].

\section{Clinical parameters}

We included in the analysis various clinicopathologic and genetic parameters that could affect NAFLD prognosis. The NAFLD fibrosis score (NFS), calculated as $(-1.675+0.037 \times$ age [years] $+0.094 \times \mathrm{BMI}$ $\left[\mathrm{kg} / \mathrm{m}^{2}\right]+1.13 \times$ impaired fasting glycemia/diabetes $[$ yes $=1, \quad$ no $=0]+0.99 \times$ aspartate aminotransferase/alanine aminotransferase ratio $-0.013 \times$ platelet $\left[\times 10^{9} / \mathrm{l}\right]-0.66 \times$ albumin $\left.[\mathrm{g} / \mathrm{dl}]\right)$, has been used as a parameter for progression of fibrosis [16]. By applying the low cutoff point (score less than -1.455), 77\% of the patients without significant fibrosis were correctly identified, whereas $22 \%$ of patients with a low cutoff point were incorrectly staged [16]. We used the Europeans definition of obesity $\left(B M I \geq 30 \mathrm{~kg} / \mathrm{m}^{2}\right)$ [17], while lean NAFLD was defined as $B M I<25.0 \mathrm{~kg} / \mathrm{m}^{2}$ [9]. Patatin-like phospholipase domain containing protein 3 (PNPLA3) rs738409, transmembrane 6 superfamily member 2 (TM6SF2) rs58542926, and hydroxysteroid 17-beta dehydrogenase
13 (HSD17B13) rs6834314 were genotyped by the TaqMan single-nucleotide polymorphism (SNP) genotyping assay (Applied Biosystems, Foster City, CA).

\section{Statistical analysis}

The baseline characteristics were compared using the Mann-Whitney U test for continuous variables or Fisher's exact test for categorical variables. The incidence of each event was analyzed during the period from the time of histopathological diagnosis of NAFLD until the last visit or occurrence of event. Overall survival was estimated using the Kaplan-Meier method, and differences between curves were evaluated using the log-rank test. All parameters that showed strong correlation with others were considered confounding factors and excluded from the statistical analysis. The remaining parameters were entered into multivariate analysis using the logistic regression analysis and the Cox proportional hazards model. Statistical significance was set at $P<0.05$. All statistical analyses were carried out using the EZR software [18].

\section{Results}

\section{Comparison of background factors stratified by BMI}

The baseline characteristics and laboratory data stratified by BMI of the 446 patients are shown in Table 2 . The prevalence of type 2 diabetes mellitus, hypertension and hyperuricemia were significantly lower in the lean NAFLD group $(\mathrm{BMI}<25)$. Aspartate aminotransferase, alanine aminotransferase, triglyceride, fasting blood sugar, glycated hemoglobin, ferritin, and NAFLD fibrosis score (NFS) were significantly lower in the lean NAFLD group. Various histopathological findings (e.g., steatosis 3 , lobular inflammation $2-3$, NAFLD activity score $5-8$, and fibrosis stage 3-4) were significantly lower in the lean NAFLD group.

\section{Incidence of various events stratified by BMI}

Table 3 lists the incidence of liver events, cardiovascular events, type 2 diabetes mellitus, and non-liver malignancies in patients with NAFLD. We analyzed the person-years method for patients with new onset during follow-up who did not have each disease before or at liver biopsy. In the lean NAFLD group, 6/155 (3.9\%) patients developed liver cancer (rate per 1000 person years, 4.49). Furthermore, $4 / 148$ (2.7\%) patients confirmed to have no previous or current liver-related events at NAFLD diagnosis developed liver-related events (rate per 1000 person years, 3.08). Furthermore, 15/168 (8.9\%) patients developed cardiovascular events, with a development rate per 1000 person years of 11.07. Further analysis showed 12/128 (9.4\%) patients developed type 2 diabetes mellitus (rate per 1000 person years, 10.95) and 12/152 
Table 2 Background factors stratified by BMI at the time of liver biopsy

\begin{tabular}{|c|c|c|c|}
\hline & Lean NAFLD ${ }^{a}$ & Non-lean NAFLD & $P$ value \\
\hline $\mathrm{n}$ & 170 & 276 & \\
\hline Age & $53(18-85)$ & $52(18-87)$ & 0.549 \\
\hline Sex, male (\%) & 61.2 & 59.4 & 0.765 \\
\hline Body mass index (kg/m2) & $23.1(18.1-24.9)$ & $28.7(25.0-42.4)$ & $<0.01$ \\
\hline History of liver cancer (\%) & 8.9 & 5.1 & 0.119 \\
\hline History on non-liver malignancy (\%) & 9.5 & 8.3 & 0.730 \\
\hline Type 2 diabetes mellitus (\%) & 23.5 & 38.4 & $<0.01$ \\
\hline Dyslipidemia (\%) & 28.2 & 37.5 & 0.051 \\
\hline Hypertension (\%) & 31.8 & 52.9 & $<0.01$ \\
\hline Hyperuricemia (\%) & 2.9 & 14.9 & $<0.01$ \\
\hline Smoking (\%) & 22.1 & 22.7 & 0.906 \\
\hline Albumin (g/dL) & $4.1(2.8-5.4)$ & $4.1(3.0-6.9)$ & 0.994 \\
\hline Aspartate aminotransferase (IU/L) & $36(12-312)$ & $51(15-378)$ & $<0.01$ \\
\hline Alanine aminotransferase (IU/L) & $53(13-458)$ & $81(15-783)$ & $<0.01$ \\
\hline Gamma-glutamyl transpeptidase (IU/L) & $72(11-786)$ & $71(16-990)$ & 0.672 \\
\hline Hemoglobin (g/dL) & $14.5(6.5-17.5)$ & $14.8(9.2-18.7)$ & 0.192 \\
\hline Platelet count $(\times 104 / \mu \mathrm{L})$ & $22.0(4.0-47.1)$ & $20.8(5.0-37.7)$ & 0.236 \\
\hline Triglyceride (mg/dL) & $130(31-1088)$ & $145(52-570)$ & 0.021 \\
\hline Total cholesterol (mg/dL) & $196(101-290)$ & $205(103-370)$ & 0.350 \\
\hline High-density lipoprotein cholesterol (mg/dL) & $47(22-85)$ & $44(14-86)$ & 0.227 \\
\hline Low-density lipoprotein cholesterol (mg/dL) & $116(27-218)$ & $124(31-243)$ & 0.073 \\
\hline Fasting blood sugar (mg/dL) & $100(70-237)$ & $105(65-287)$ & $<0.01$ \\
\hline Glycated hemoglobin (\%) & $5.8(4.4-10.8)$ & $6.0(4.3-12.6)$ & 0.027 \\
\hline Ferritin (ng/mL) & $191(10-1472)$ & $249(1-2067)$ & $<0.01$ \\
\hline NAFLD fibrosis score & $-2.415(-7.060$ to 3.095$)$ & $-1.550(-5.481$ to 3.394$)$ & $<0.01$ \\
\hline \multicolumn{4}{|l|}{ Genetic variation } \\
\hline Cases tested, (n) & 110 & 204 & \\
\hline PNPLA3 rs738409, GG (\%) & 41.8 & 41.7 & 1.000 \\
\hline TM6SF2 rs58542926, non CC (\%) & 26.4 & 23.5 & 0.585 \\
\hline HSD17B13 rs6834314, non AA (\%) & 56.4 & 45.7 & 0.078 \\
\hline \multicolumn{4}{|l|}{ Histopathological findings } \\
\hline Cases examined, (n) & 170 & 276 & \\
\hline Steatosis $3(\%)^{c}$ & 18.9 & 29.2 & 0.018 \\
\hline Ballooning $2(\%)^{d}$ & 22.5 & 29.9 & 0.099 \\
\hline Lobular inflammation 2-3 (\%) & 23.7 & 44.2 & $<0.01$ \\
\hline NAFLD activity score 5-8 (\%) & 34.9 & 58.0 & $<0.01$ \\
\hline Fibrosis stage 3-4 (\%) & 22.4 & 38.4 & $<0.01$ \\
\hline
\end{tabular}

Data are number of patients or median (range) values

$P$ value by Mann-Whitney $U$ test for continuous parameters and Fisher's exact test for categorical parameters

a Lean NAFLD, BMI $<25.0 \mathrm{~kg} / \mathrm{m}^{2}$, ${ }^{b}$ non-lean NAFLD, BMI $\geq 25.0 \mathrm{~kg} / \mathrm{m}^{2}$, 'Steatosis 3 , steatosis of $\geq 66 \%$ of hepatocytes, ${ }^{\mathrm{d} B a l l o o n i n g ~} 2$, hepatocyte ballooning of many

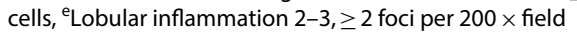

(7.9\%) patients developed non-liver malignancies (rate per 1000 person years, 9.60). The liver cancer development rate per 1000 person years tended to be higher in the lean NAFLD group (4.49) than the non-lean group (1.76). On the other hand, the proportion of patients with T2DM was lower in the lean group than the non-lean group (10.95 vs 19.88).

\section{Mortality stratified by BMI}

Table 4 lists the number and rate of mortality associated with liver-related events, non-liver cancer malignancies, and other events in patients with NAFLD. A person-year analysis was performed on patients who did not have the disease before or at the time of liver biopsy and died of the disease during follow-up. For the lean NAFLD group, 
Table 3 Incidence of liver events, cardiovascular events, type 2 diabetes mellitus, and non-liver malignancies in patients with NAFLD

\begin{tabular}{|c|c|c|c|c|c|c|}
\hline \multirow[t]{2}{*}{ Events } & \multicolumn{2}{|l|}{ Overall } & \multicolumn{2}{|l|}{ Lean NAFLD ${ }^{a}$} & \multicolumn{2}{|c|}{ Non-lean NAFLD ${ }^{b}$} \\
\hline & $\mathrm{n} / \mathrm{N}(\%)$ & $\begin{array}{l}1000 \text { person } \\
\text { years }\end{array}$ & $\mathrm{n} / \mathrm{N}(\%)$ & $\begin{array}{l}1000 \text { person } \\
\text { years }\end{array}$ & $\mathrm{n} / \mathrm{N}(\%)$ & $\begin{array}{l}1000 \\
\text { person } \\
\text { years }\end{array}$ \\
\hline Liver-related events & $11 / 405(2.7 \%)$ & 3.72 & $4 / 148(2.7 \%)$ & 3.08 & $7 / 257(2.7 \%)$ & 4.23 \\
\hline Liver cancer & $9 / 418(2.2 \%)$ & 2.96 & 6/155 (3.9\%) & 4.49 & 3/263 (1.1\%) & 1.76 \\
\hline Hepatic encephalopathy & $6 / 444(1.4 \%)$ & 1.86 & 3/168 (1.8\%) & 2.11 & $3 / 276(1.1 \%)$ & 1.67 \\
\hline Esophagogastric varices & $7 / 432(1.6 \%)$ & 2.22 & 3/163 (1.8\%) & 2.16 & 4/269 (1.1\%) & 2.26 \\
\hline Ascites & $9 / 441(2.0 \%)$ & 2.80 & 4/167 (2.4\%) & 2.82 & $5 / 274(1.8 \%)$ & 2.78 \\
\hline Jaundice & $3 / 442(0.7 \%)$ & 0.93 & 0/167 (0.0\%) & 0.00 & 3/275 (1.1\%) & 1.68 \\
\hline Cardiovascular events & $36 / 443(8.1 \%)$ & 11.72 & 15/168 (8.9\%) & 11.07 & $21 / 275(7.6 \%)$ & 12.24 \\
\hline Type 2 diabetes mellitus & $34 / 298(11.4 \%)$ & 15.43 & $12 / 128(9.4 \%)$ & 10.95 & $22 / 170(12.9 \%)$ & 19.88 \\
\hline Non-liver malignancies & $26 / 406$ (6.4\%) & 9.06 & $12 / 152(7.9 \%)$ & 9.60 & $14 / 254(5.5 \%)$ & 8.65 \\
\hline
\end{tabular}

$\mathrm{n}$; number of events, $\mathrm{N}$; number of patients free or with the respective event at the time of NAFLD diagnosis

${ }^{a}$ Lean NAFLD, BMI $<25.0 \mathrm{~kg} / \mathrm{m}^{2}$, bnon-lean NAFLD, BMI $\geq 25.0 \mathrm{~kg} / \mathrm{m}^{2}$

Table 4 causes of mortality in patients with NAFLD

\begin{tabular}{|c|c|c|c|c|c|c|}
\hline \multirow[t]{2}{*}{ Cause of death } & \multicolumn{2}{|l|}{ Overall } & \multicolumn{2}{|l|}{ Lean NAFLD } & \multicolumn{2}{|c|}{ Non-lean NAFLD ${ }^{\mathbf{b}}$} \\
\hline & n/N (\%) & $\begin{array}{l}1000 \text { person } \\
\text { years }\end{array}$ & n/N (\%) & $\begin{array}{l}1000 \text { person } \\
\text { years }\end{array}$ & n/N (\%) & $\begin{array}{l}1000 \\
\text { person } \\
\text { years }\end{array}$ \\
\hline Overall & $9 / 360(2.5 \%)$ & 3.31 & 4/132 (3.0\%) & 3.32 & $5 / 228(2.2 \%)$ & 3.31 \\
\hline Liver-related events & $5 / 360(1.4 \%)$ & 1.84 & $3 / 132(2.3 \%)$ & 2.49 & 2/228 (0.9\%) & 1.32 \\
\hline Non-liver malignancies & 2/360 (0.6\%) & 0.74 & $1 / 132(0.8 \%)$ & 0.83 & $1 / 228(0.4 \%)$ & 0.66 \\
\hline Other events * & $2 / 360(0.6 \%)$ & 0.74 & 0/132 (0.0\%) & 0.00 & 2/228 (0.9\%) & 1.32 \\
\hline
\end{tabular}

$\mathrm{n}$; number of events. $\mathrm{N}$; number of patients with or without the respective event at the time of NAFLD diagnosis

a Lean NAFLD, BMI $<25.0 \mathrm{~kg} / \mathrm{m}^{2}$, non-lean NAFLD, BMI $\geq 25.0 \mathrm{~kg} / \mathrm{m}^{2}$

* Sepsis and interstitial pneumonia

4/132 (3.0\%) patients died during the study (per 1000 person-years, 3.32), with liver-related events in $3(2.3 \%)$ (rate per 1000 person years, 2.49) and non-liver cancer malignancy in $1(0.8 \%)$ (rate per 1000 person years, 0.83). Deaths from liver-related diseases tended to be more common in the lean NAFLD group than the nonlean NAFLD group, but the difference was not statistically significant. Kaplan-Meier analysis also showed no significant difference in overall survival between the two groups $(P=0.39)$ (Fig. 1).

\section{Non-invasive predictors of severe fibrosis (stage 3-4) in patients with lean NAFLD}

Table 5 summarizes the baseline characteristics and laboratory data of the 170 patients with lean NAFLD ( $\mathrm{n}=132$, with fibrosis stage $0-2, \mathrm{n}=38$ for fibrosis stage 3-4). Age, history of liver cancer and prevalence of type 2 diabetes mellitus were significantly higher in patients with fibrosis stage 3-4. Furthermore, hemoglobin, platelet count, total cholesterol, and lowdensity lipoprotein cholesterol were significantly lower, while aspartate aminotransferase, fasting blood sugar, glycated hemoglobin, and NFS were significantly higher in patients with fibrosis stage 3-4. PNPLA3 GG was significantly more frequent in the group of fibrosis stage 3-4. For histopathological findings, ballooning 2 and lobular inflammation $2-3$ were significantly more frequent in the fibrosis score 3-4 group.

All parameters that correlated strongly with others were considered confounding factors and excluded from statistical analysis. Thus, 14 non-invasive potential predictive factors of severe fibrosis (stage 3-4) were analyzed (Table 6). Univariate analysis identified four significant parameters; history of liver cancer, hemoglobin, NFS, and PNPLA3. These parameters were entered into multivariate analysis using the logistic regression analysis. The results identified NFS as a significant and independent factor determinant of 


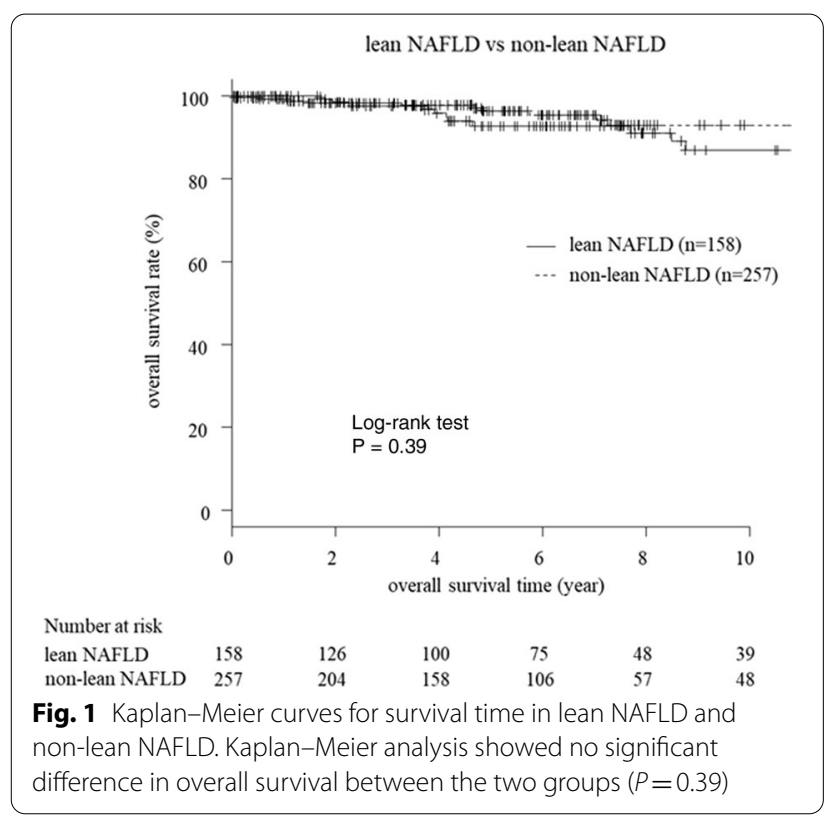

development of severe fibrosis (stage $3-4)(\geq-1.455$, $P<0.01$ ) (Table 6).

\section{Non-invasive predictors of survival in patients with lean NAFLD}

Parameters that correlated strongly with others were considered confounding factors and excluded from statistical analysis. Thus, 14 non-invasive potential predictive factors of prognosis were analyzed (Table 7). Univariate analysis showed that history of previous liver cancer and NFS correlated significantly with survival. These two factors were entered into multivariate analysis using the Cox proportional hazards model. The analysis identified both parameters as significant and independent prognostic factors for lean NAFLD (yes for history of liver cancer, $P<0.01$, NFS: $\geq-1.455, P=0.026$ ) (Table 7). Furthermore, Kaplan-Meier analysis also showed that overall survival was significantly shorter in patients with previous liver cancer $(P<0.01)$ and in those with high NFS $(\geq-1.455, P<0.014)$ (Fig. 2).

\section{Discussion}

The clinical characteristics and prognostic factors of lean NAFLD remains unclear. In this retrospective study, we investigated the clinical features of histopathologicallyconfirmed cases of lean NAFLD and analyzed clinically useful parameters obtained non-invasively for the prediction of severe fibrosis and prognosis.

Our study included 170 patients with lean NAFLD and 276 with non-lean NAFLD. Lean NAFLD was associated with a lower complication rate of metabolic syndrome and better general biochemical data and pathological findings than the non-lean NAFLD. However, the rates of liver-related events, cardiovascular events, and malignancies were not different between the two groups, though the incidence of liver cancer was particularly higher in lean NAFLD. The overall survival rate was not significantly different between the two groups. Previous studies suggested that the metabolic profile of lean NAFLD is similar or slightly better than that of the nonlean NAFLD $[19,20]$, which was also noted in this study. The finding that patients with lean NAFLD are at higher risk of severe liver disease despite the lower prevalence of advanced fibrosis and NASH at baseline is paradoxical. Logically, this suggests that progression of liver fibrosis is faster in lean NAFLD than in NAFLD obese patients [9]. Further studies are needed to confirm this speculation.

Several studies have described age, diabetes, cirrhosis, low platelet count and low albumin levels as significant prognostic factors for NAFLD/NASH [21-28]. Although there are only a few reports on the prognostic factors of lean NAFLD among NAFLDs, one previous study identified fibrosis stage, hypertension, and age as independent prognostic factors [9]. As mentioned above, lean NAFLD patients have shorter history and less abnormal laboratory findings than those with non-lean NAFLD. Analysis of non-invasive predictors of fibrosis and prognosis of lean NAFLD is needed because early intervention is needed to improve prognosis. Such non-invasive markers should serve to: i) in primary care settings, identify the risk of NAFLD among individuals with increased metabolic risk; ii) in secondary and tertiary care settings, identify those with worse prognosis, e.g. severe NASH; iii) monitor disease progression; and iv) predict response to therapeutic interventions. Achieving these objectives could reduce the need for liver biopsy [8]. NFS or FIB-4 index are clinically useful tools for identifying NAFLD patients with higher likelihood of having bridging fibrosis (stage 3) or cirrhosis (stage 4) [29, 30]. The NAFLD fibrosis score (NFS) has the advantage that no special test items are included. We identified NFS of $\geq-1.455$ as a non-invasively measured parameter for the prediction of severe fibrosis in lean NAFLD. More importantly, for the first time, we found that NFS of $\geq-1.455$ is also a non-invasive independent and significant predictor of prognosis.

The present study has certain limitations. First, the median observation period was 4.6 years, which is a relatively short in prognostic studies. Second, the subject of this study were patient admitted to the Department of Hepatology of our hospital for liver biopsy. All subjects were Asians and admitted for the purpose of scrutiny of liver disease. Thus, a selection bias cannot be excluded. Further studies are needed that include patients of 
Table 5 Background factors in patients with lean NAFLD stratified by fibrosis stage

\begin{tabular}{|c|c|c|c|}
\hline & Fibrosis stage $0-2(n=132)$ & Fibrosis stage $3-4(n=38)$ & $P$ value \\
\hline Age & $49(18-79)$ & $67(28-85)$ & $<0.01$ \\
\hline Sex, male (\%) & 64.4 & 50.0 & 0.132 \\
\hline BMI (kg/m2) & $23.1(18.8-24.8)$ & $23.3(18.1-24.9)$ & 0.388 \\
\hline History of liver cancer (\%) & 4.6 & 23.7 & $<0.01$ \\
\hline History of non-liver malignancy (\%) & 6.9 & 18.4 & 0.054 \\
\hline Type 2 diabetes mellitus (\%) & 16.2 & 50.0 & $<0.01$ \\
\hline Dyslipidemia (\%) & 25.8 & 36.8 & 0.220 \\
\hline Hypertension (\%) & 29.5 & 39.5 & 0.323 \\
\hline Hyperuricemia (\%) & 2.3 & 5.3 & 0.311 \\
\hline Smoking (\%) & 22.8 & 19.4 & 0.821 \\
\hline Albumin (g/dL) & $4.1(2.8-5.4)$ & $4.1(2.8-4.9)$ & 0.083 \\
\hline Aspartate aminotransferase (IU/L) & $36(12-312)$ & $46(17-139)$ & $<0.01$ \\
\hline Alanine aminotransferase (IU/L) & $56(13-458)$ & $41(17-280)$ & 0.311 \\
\hline Gamma-glutamyl transpeptidase (IU/L) & $79(11-786)$ & $63(17-285)$ & 0.184 \\
\hline Hemoglobin (g/dL) & $14.7(10.1-17.5)$ & $13.9(6.5-16.4)$ & $<0.01$ \\
\hline Platelet count $\left(\times 10^{4} / \mu \mathrm{L}\right)$ & $23.8(9.8-47.1)$ & $15.5(4.0-32.8)$ & $<0.01$ \\
\hline Triglyceride (mg/dL) & $131(31-1088)$ & $125(36-610)$ & 0.287 \\
\hline Total cholesterol (mg/dL) & $202(101-290)$ & $178(101-280)$ & $<0.01$ \\
\hline High-density lipoprotein cholesterol (mg/dL) & $47(23-85)$ & $45(22-85)$ & 0.589 \\
\hline Low-density lipoprotein cholesterol (mg/dL) & $117(27-218)$ & $95(29-185)$ & $<0.01$ \\
\hline Fasting blood sugar (mg/dL) & $98(70-159)$ & $118(76-237)$ & $<0.01$ \\
\hline Glycated hemoglobin (\%) & $5.7(4.7-9.3)$ & $6.1(4.4-10.8)$ & 0.022 \\
\hline Ferritin $(\mathrm{ng} / \mathrm{mL})$ & $180(10-697)$ & $231(10-1472)$ & 0.083 \\
\hline NAFLD fibrosis score & $-2.862(-7.060$ to 1.566$)$ & $-0.193(-4.723$ to 3.095$)$ & $<0.01$ \\
\hline \multicolumn{4}{|l|}{ Genetic variation } \\
\hline Cases tested, (n) & 83 & 27 & \\
\hline PNPLA3 rs738409, GG (\%) & 34.9 & 63.0 & 0.014 \\
\hline TM6SF2 rs58542926, non CC (\%) & 25.3 & 29.6 & 0.802 \\
\hline HSD17B13 rs6834314, non AA (\%) & 54.2 & 63.0 & 0.506 \\
\hline \multicolumn{4}{|l|}{ Histopathological findings } \\
\hline Cases tested, (n) & 132 & 37 & \\
\hline Steatosis $3(\%)$ & 18.9 & 18.9 & 1 \\
\hline Ballooning 2 (\%) & 15.9 & 45.9 & $<0.01$ \\
\hline Lobular inflammation 2-3 (\%) & 18.9 & 40.5 & $<0.01$ \\
\hline NAFLD activity score 5-8 (\%) & 31.1 & 48.6 & 0.053 \\
\hline
\end{tabular}

Data are number of patients or median (range) values

$P$ value by Mann-Whitney $U$ test for continuous parameters and Fisher's exact test for categorical parameters

a Steatosis 3 , steatosis of $\geq 66 \%$ of hepatocytes, ${ }^{b}$ Ballooning 2 , hepatocyte ballooning of many cells, 'Lobular inflammation $2-3, \geq 2$ foci per $200 \times$ field

different races and healthy people followed for longer periods.

\section{Conclusions}

Although patients with lean NAFLD had better histologic and biochemical profile compared to patients with non-lean NAFLD, it may be risky to end those follow-ups based on the lack of differences in prognosis between the two groups. In lean NAFLD, patients with NAFLD fibrosis score of $\geq-1.455$ or history of liver cancer should be followed-up carefully. 
Table 6 Predictors of severe fibrosis (stage 3-4) in patients with lean NAFLD

\begin{tabular}{|c|c|c|c|c|c|c|}
\hline & \multicolumn{3}{|c|}{ Univariate } & \multicolumn{3}{|c|}{ Multivariate } \\
\hline & OR & $(95 \% \mathrm{Cl})$ & $P$ value & OR & $(95 \% \mathrm{Cl})$ & $P$ value \\
\hline \multicolumn{7}{|l|}{ Sex } \\
\hline Female & 1.8 & $(0.81-4.00)$ & 0.132 & & & \\
\hline Male & 1 & & & & & \\
\hline \multicolumn{7}{|c|}{ History of liver cancer } \\
\hline Yes & 6.37 & $(1.86-23.60)$ & 0.001 & 2.05 & $(0.37-11.40)$ & 0.411 \\
\hline No & 1 & & & 1 & & \\
\hline \multicolumn{7}{|c|}{ History on non-liver malignancy } \\
\hline Yes & 3.01 & $(0.88-9.93)$ & 0.054 & & & \\
\hline No & 1 & & & & & \\
\hline \multicolumn{7}{|l|}{ Dyslipidemia } \\
\hline Yes & 1.68 & $(0.72-3.83)$ & 0.220 & & & \\
\hline No & 1 & & & & & \\
\hline \multicolumn{7}{|c|}{ Hypertension } \\
\hline Yes & 1.55 & $(0.68-3.49)$ & 0.323 & & & \\
\hline No & 1 & & & & & \\
\hline \multicolumn{7}{|c|}{ Hyperuricemia } \\
\hline Yes & 2.37 & $(0.19-21.56)$ & 0.311 & & & \\
\hline No & 1 & & & & & \\
\hline \multicolumn{7}{|l|}{ Smoking } \\
\hline No & 1.22 & $(0.46-3.66)$ & 0.821 & & & \\
\hline Yes & 1 & & & & & \\
\hline \multicolumn{7}{|c|}{ Gamma-glutamyl transpeptidase (IU/L) } \\
\hline$<71$ & 1.35 & $(0.62-3.00)$ & 0.464 & & & \\
\hline$\geq 71$ & 1 & & & & & \\
\hline \multicolumn{7}{|c|}{ Hemoglobin (g/dL) } \\
\hline$\leq 14.5$ & 2.16 & $(0.97-5.03)$ & 0.045 & 1.37 & $(0.43-4.36)$ & 0.594 \\
\hline$>14.5$ & 1 & & & 1 & & \\
\hline \multicolumn{7}{|c|}{ Ferritin (ng/mL) } \\
\hline$\geq 180$ & 1.16 & $(0.52-2.61)$ & 0.711 & & & \\
\hline \multicolumn{7}{|l|}{$<180$} \\
\hline \multicolumn{7}{|c|}{ NAFLD fibrosis score } \\
\hline$\geq-1.455$ & 16.49 & $(6.43-47.12)$ & $<0.01$ & 14.60 & $(4.50-47.20)$ & $<0.01$ \\
\hline$<-1.455$ & 1 & & & 1 & & \\
\hline \multicolumn{7}{|c|}{ PNPLA3 rs738409 } \\
\hline GG & 3.13 & $(1.18-8.74)$ & 0.014 & 1.78 & $(0.58-5.44)$ & 0.312 \\
\hline Non GG & 1 & & & 1 & & \\
\hline \multicolumn{7}{|c|}{ TM6SF2 rs58542926 } \\
\hline Non CC & 1.24 & $(0.41-3.53)$ & 0.802 & & & \\
\hline $\mathrm{CC}$ & 1 & & & & & \\
\hline \multicolumn{7}{|c|}{ HSD17B13 rs6834314 } \\
\hline Non AA & 1.43 & $(0.54-3.94)$ & 0.506 & & & \\
\hline AA & 1 & & & & & \\
\hline
\end{tabular}

Parameters that correlated significantly with other variables were considered confounding factors and excluded from statistical analysis $P$ values by logistic regression analysis 
Table 7 Predictors of survival of patients with lean NAFLD

\begin{tabular}{|c|c|c|c|c|c|c|}
\hline & \multicolumn{3}{|l|}{ Univariate } & \multicolumn{3}{|c|}{ Multivariate } \\
\hline & HR & $(95 \% \mathrm{Cl})$ & $P$ value & HR & $(95 \% \mathrm{Cl})$ & $P$ value \\
\hline \multicolumn{7}{|l|}{ Sex } \\
\hline Male & 1.47 & $(0.45-4.83)$ & 0.526 & & & \\
\hline Female & 1 & & & & & \\
\hline \multicolumn{7}{|c|}{ History of liver cancer } \\
\hline Yes & 15.89 & $(4.62-54.62)$ & $<0.01$ & 7.17 & $(1.76-29.23)$ & $<0.01$ \\
\hline No & 1 & & & & & \\
\hline \multicolumn{7}{|c|}{ History of non-liver malignancy } \\
\hline Yes & 2.89 & $(0.60-13.99)$ & 0.186 & & & \\
\hline No & 1 & & & & & \\
\hline \multicolumn{7}{|l|}{ Dyslipidemia } \\
\hline No & 3.88 & $(0.50-30.35)$ & 0.196 & & & \\
\hline Yes & 1 & & & & & \\
\hline \multicolumn{7}{|c|}{ Hypertension } \\
\hline Yes & 1.33 & $(0.39-4.53)$ & 0.653 & & & \\
\hline No & 1 & & & & & \\
\hline \multicolumn{7}{|c|}{ Hyperuricemia } \\
\hline No & $25,570,000$ & $(0.00-\infty)$ & 0.998 & & & \\
\hline Yes & 1 & & & & & \\
\hline \multicolumn{7}{|l|}{ Smoking } \\
\hline No & 1.09 & $(0.23-5.12)$ & 0.916 & & & \\
\hline Yes & 1 & & & & & \\
\hline \multicolumn{7}{|c|}{ Gamma-glutamyl transpeptidase (IU/L) } \\
\hline$\geq 71$ & 1.18 & $(0.36-3.87)$ & 0.786 & & & \\
\hline$<71$ & 1 & & & & & \\
\hline \multicolumn{7}{|c|}{ Hemoglobin (g/dL) } \\
\hline$\leq 14.5$ & 1.76 & $(0.51-6.01)$ & 0.369 & & & \\
\hline$>14.5$ & 1 & & & & & \\
\hline \multicolumn{7}{|c|}{ Ferritin (ng/mL) } \\
\hline$\geq 180$ & 1.33 & $(0.40-4.40)$ & 0.640 & & & \\
\hline$<180$ & 1 & & & & & \\
\hline \multicolumn{7}{|c|}{ NAFLD fibrosis score } \\
\hline$\geq-1.455$ & 31.43 & $(3.90-253.2)$ & $<0.01$ & 12.87 & $(1.35-122.30)$ & 0.026 \\
\hline$<-1.455$ & 1 & & & & & \\
\hline \multicolumn{7}{|c|}{ PNPLA3 rs738409 } \\
\hline GG & 2.55 & $(0.61-10.73)$ & 0.202 & & & \\
\hline Non GG & 1 & & & & & \\
\hline \multicolumn{7}{|c|}{ TM6SF2 rs58542926 } \\
\hline CC & 2.19 & $(0.27-17.82)$ & 0.463 & & & \\
\hline Non CC & 1 & & & & & \\
\hline \multicolumn{7}{|c|}{ HSD17B13 rs6834314 } \\
\hline Non AA & 1.03 & $(0.252-4.066)$ & 0.986 & & & \\
\hline AA & 1 & & & & & \\
\hline
\end{tabular}

Parameters that correlated significantly with other variables were considered confounding factors and excluded from statistical analysis P values by Cox proportional hazards model 
a History of liver cancer

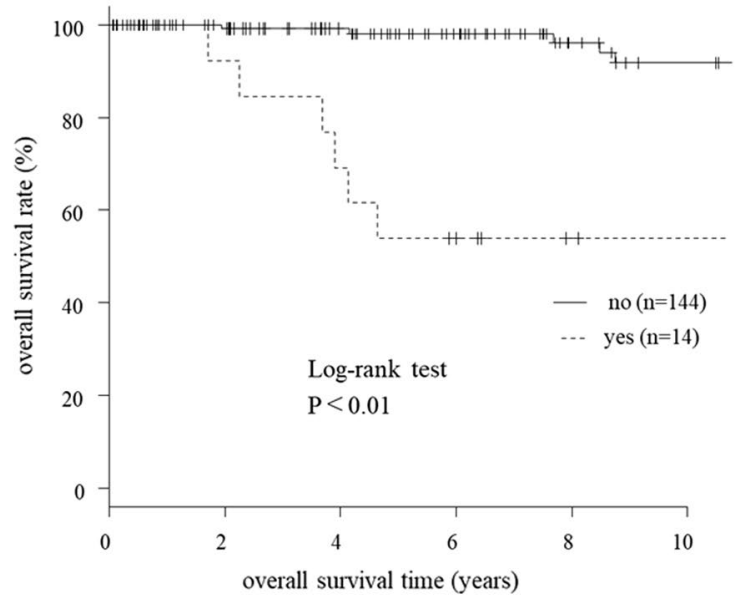

b NAFLD fibrosis score (NFS)

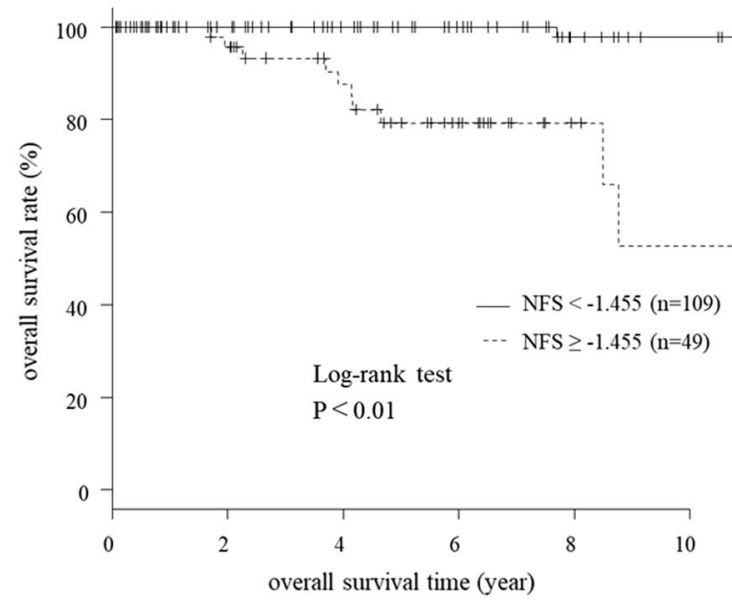

Number at risk

NFS $<-1.455 \quad 109$

NFS $\geq-1.455 \quad 49$

overall survival time (year)

83

43

68

55

41

35

Number at risk

$\begin{array}{lcccccc}\text { no } & 144 & 114 & 91 & 69 & 46 & 38 \\ \text { yes } & 14 & 12 & 9 & 6 & 2 & 1\end{array}$

Fig. 2 Kaplan-Meier curves for survival time in lean NAFLD stratified by a history of liver cancer and $\mathbf{b}$ NAFLD fibrosis score. The analysis showed a significantly shorter overall survival in patients with previous liver cancer (yes, $P<0.01)$ and with higher NFS $(\geq-1.455, P<0.014)$

\section{Abbreviations}

BMI: Body mass index; Cl: Confidence interval; HCV: Hepatitis C virus; HR: Hazard ratio; HSD17B13: Hydroxysteroid 17-beta dehydrogenase 13; NAFLD: Nonalcoholic fatty liver disease; NASH: Nonalcoholic steatohepatitis; NPR: Patient Register of Hospital Discharges; OR: Odds ratio; PNPLA3: Patatin-like phospholipase domain-containing 3; T2DM: Type 2 diabetes mellitus; TM6SF2: Transmembrane 6 superfamily member 2 .

\section{Acknowledgements}

The authors thank Drs. Keiichi Kinowaki and Takeshi Fujii (Department of Pathology, Toranomon Hospital) and also Drs. Fukuo Kondo and Toshio Fukusato (Department of Pathology, Teikyo University School of Medicine) for assistance in histopathological diagnosis.

\section{Authors' contributions}

SI, NA, YK, AK, KK, SF, HS, TH, MK (Masahiro Kobayashi), MK (Mariko Kobayashi), SS, FS, YA, KI, YS, and HK contributed to this work. SI and NA analyzed the data. SI wrote the manuscript. All authors read and approved the final manuscript.

\section{Funding}

This study was supported co-research expenses in part by a Grant-in-Aid from the Japan Agency for Medical Research and Development to NA (\#JP20fk0210040 and \#JP20fk0210073) and a Grant-in-Aid for scientific research and development from the Ministry of Health, Labour and Welfare of Japan to NA (\#19HC1001).

\section{Availability of data and materials}

The datasets generated and/or analyzed in the present study are available from the corresponding author on reasonable request.

\section{Ethics approval and consent to participate}

The study was conducted in compliance with the International Conference on Harmonization guidelines for Good Clinical Practice (E6) and the 2013 Declaration of Helsinki. The protocol was approved by the institutional review board at Toranomon Hospital (number; 953). Written informed consent was provided by all patients prior to liver biopsy.

\section{Consent for publication}

Not Applicable.

\section{Competing interests}

(1) Hiromitsu Kumada has received honoraria from MSD K.K., Gilead Sciences, AbbVie Inc., Eisai Co., Ltd, and Dainippon Sumitomo Pharma. (2) Norio Akuta has received honoraria from AbbVie Inc and Gilead Sciences. (3) Yasuji Arase has received honorarium from AbbVie Inc. (4) Masahiro Kobayashi has received honoraria from Eisai Co., Ltd. (5) Yusuke Kawamura has received honoraria from Eisai Co., Ltd. All other authors declare no competing interests.

\section{Author details}

${ }^{1}$ Department of Hepatology, Toranomon Hospital and Okinaka Memorial Institute for Medical Research, 2-2-2 Toranomon, Minato-ku, Tokyo 105-8470, Japan. ${ }^{2}$ Liver Research Laboratory, Toranomon Hospital, Tokyo, Japan.

Received: 2 September 2020 Accepted: 20 October 2020

Published online: 04 November 2020

\section{References}

1. Angulo P. Nonalcoholic fatty liver disease. N Engl J Med. 2002;346:1221-31.

2. Williams R. Global changes in liver disease. Hepatology. 2006;44:521-6.

3. Torres DM, Harrison SA. Diagnosis and therapy of nonalcoholic steatohepatitis. Gastroenterology. 2008;134:1682-98.

4. Vuppalanchi R, Chalasani N. Nonalcoholic fatty liver disease and nonalcoholic steatohepatitis: selected practical issues in their evaluation and management. Hepatology. 2009;49:306-17.

5. Kawamura Y, Arase Y, Ikeda K, Seko Y, Imai N, Hosaka T, et al. Large-scale long-term follow-up study of Japanese patients with non-alcoholic fatty liver disease for the onset of hepatocellular carcinoma. Am J Gastroenterol. 2012;107:253-61.

6. Sumida Y, Nakajima A, Itoh Y. Limitations of liver biopsy and noninvasive diagnostic tests for the diagnosis of nonalcoholic fatty liver disease/nonalcoholic steatohepatitis. World J Gastroenterol. 2014;20:475-85.

7. Kleiner DE, Brunt EM. Nonalcoholic fatty liver disease: pathologic patterns and biopsy evaluation in clinical research. Semin Liver Dis. 2012;32:3-13.

8. European Association for the Study of the Liver (EASL), European Association for the Study of Diabetes (EASD), European Association for the 
Study of Obesity (EASO). EASL-EASD-EASO Clinical Practice Guidelines for the management of non-alcoholic fatty liver disease. J Hepatol. 2016;64:1388-402.

9. Hagström H, Nasr P, Ekstedt M, et al. Risk for development of severe liver disease in lean patients with nonalcoholic fatty liver disease: a long-term follow-up study. Hepatol Commun. 2017;2:48-57.

10. Leung JC, Loong TC, Wei JL, Wong GL, Chan AW, Choi PC, et al. Histological severity and clinical outcomes of nonalcoholic fatty liver disease in nonobese patients. Hepatology. 2017;65:54-64.

11. Dela Cruz AC, Bugianesi E, George J, Day CP, Liaquat H, Charatcharoenwitthaya $\mathrm{P}$, et al. Characteristics and long-term prognosis of lean patients with nonalcoholic fatty liver disease. Gastroenterology. 2014;146(Suppl. 1):S-909.

12. Golabi P, Paik J, Fukui N, Locklear CT, de Avilla L, Younossi ZM. Patients with lean nonalcoholic fatty liver disease are metabolically abnormal and have a higher risk for mortality. Clin Diabetes. 2019;37:65-72.

13. Kleiner DE, Brunt EM, Van Natta M, Behling C, Contos MJ, Cummings OW, et al. Nonalcoholic steatohepatitis clinical research network. Design and validation of a histological scoring system for nonalcoholic fatty liver disease. Hepatology. 2005:41:1313-21.

14. Brunt EM, Janney CG, Di Bisceglie AM, Neuschwander-Tetri BA, Bacon BR. Nonalcoholic steatohepatitis: a proposal for grading and staging the histological lesions. Am J Gastroenterol. 1999;94:2467-74.

15. Bedossa P; FLIP Pathology Consortium. Utility and appropriateness of the fatty liver inhibition of progression (FLIP) algorithm and steatosis, activity, and fibrosis (SAF) score in the evaluation of biopsies of nonalcoholic fatty liver disease. Hepatology. 2014;60:565-655.

16. Angulo P, Hui JM, Marchesini G, Bugianesi E, George J, Farrell GC, et al. The NAFLD fibrosis score: a non-invasive system that identifies liver fibrosis in patients with NAFLD. Hepatology. 2007:45:846-54.

17. Alberti KG, Zimmet P, Shaw J, IDF Epidemiology Task Force Consensus Group. The metabolic syndrome-a new worldwide definition. Lancet. 2005:366:1059-62.

18. Kanda Y. Investigation of the freely available easy-to-use software "EZR" for medical statistics. Bone Marrow Transplant. 2013:48:452-8.

19. Sookoian S, Pirola CJ. Systematic review with meta-analysis: risk factors for non-alcoholic fatty liver disease suggest a shared altered metabolic and cardiovascular profile between lean and obese patients. Aliment Pharmacol Ther. 2017;46:85-95.

20. Feldman A, Eder SK, Felder TK, Kedenko L, Paulweber B, Stadlmayr A, et al. Clinical and metabolic characterization of lean Caucasian subjects with non-alcoholic fatty liver. Am J Gastroenterol. 2017;112:102-10.
21. Teli MR, James OF, Burt AD, Bennett MK, Day CP. The natural history of nonalcoholic fatty liver: a follow-up study. Hepatology. 1995;22:1714-9.

22. Dam-Larsen $S$, Becker U, Franzmann MB, Larsen $K$, Christoffersen P, Bendtsen F. Final results of a long-term, clinical follow-up in fatty liver patients. Scand J Gastroenterol. 2009:44:1236-43.

23. Jepsen P, Vilstrup H, Mellemkjaer L, Thulstrup AM, Olsen JH, Baron JA, et al. Prognosis of patients with a diagnosis of fatty liver-a registry-based cohort study. Hepatogastroenterology. 2003;50:2101-4.

24. Söderberg C, Stål P, Askling J, Glaumann H, Lindberg G, Marmur J, et al. Decreased survival of subjects with elevated liver function tests during a 28-year follow-up. Hepatology. 2010;51:595-602.

25. Adams LA, Lymp JF, St Sauver J, Sanderson SO, Lindor KD, Feldstein A, et al. The natural history of nonalcoholic fatty liver disease: a populationbased cohort study. Gastroenterology. 2005;129:113-21.

26. Rafiq N, Bai C, Fang Y, Srishord M, McCullough A, Gramlich T, et al. Longterm follow-up of patients with nonalcoholic fatty liver. Clin Gastroentero Hepatol. 2009;7:234-8.

27. Ekstedt M, Franzén LE, Mathiesen UL, Thorelius L, Holmqvist M, Bodemar $\mathrm{G}$, et al. Long-term follow-up of patients with NAFLD and elevated liver enzymes. Hepatology. 2006;44:865-73.

28. Calori G, Lattuada G, Ragogna F, Garancini MP, Crosignani P, Villa M, et al. Fatty liver index and mortality: the Cremona study in the 15th year of follow-up. Hepatology. 2011;54:145-52.

29. Chalasani N, Younossi Z, Lavine JE, Charlton M, Cusi K, Rinella M, et al. The diagnosis and management of nonalcoholic fatty liver disease: practice guidance from the American Association for the Study of Liver Diseases. Hepatology. 2018:67:328-57.

30. Akuta N, Kawamura Y, Arase Y, Saitoh S, Fujiyama S, Sezaki H, et al. Circulating microRNA-122 and fibrosis stage predict mortality of Japanese patients with histopathologically confirmed NAFLD. Hepatol Commun. 2019;4:66-76.

\section{Publisher's Note}

Springer Nature remains neutral with regard to jurisdictional claims in published maps and institutional affiliations.

Ready to submit your research? Choose BMC and benefit from:

- fast, convenient online submission

- thorough peer review by experienced researchers in your field

- rapid publication on acceptance

- support for research data, including large and complex data types

- gold Open Access which fosters wider collaboration and increased citations

- maximum visibility for your research: over 100M website views per year

At BMC, research is always in progress.

Learn more biomedcentral.com/submissions 